\title{
Detection and Grading of Early-Stage Cochlear Damage in Land Hunters by Comparison of Extended High-Frequency Audiograms with Conventional High-Frequency Audiograms
}

\author{
Remzi Tinazli ${ }^{1}$ and Mehtap Tinazli ${ }^{2}$ \\ Departments of ${ }^{1}$ ENT and ${ }^{2}$ Internal Medicine, Medical School Hospital, Near East University, Nicosia, Cyprus
}

\author{
Received October 20, 2021 \\ Revised November 23, 2021 \\ Accepted November 26, 2021 \\ Address for correspondence \\ Remzi Tinazli, MD, PhD \\ Department of ENT, \\ Medical School Hospital, \\ Near East University, \\ Nicosia, Cyprus \\ Tel +357-90-392-6751000 \\ Fax +357-90-392-6751090 \\ E-mail remtinazli@hotmail.com
}

\begin{abstract}
Background and Objectives: Firearms used by hunters produce intermittent loud noises. These sounds, which are above the safe limits set by the World Health Organization, can cause cochlear damage. Detection of cochlear damage at an early stage, before clinical complaints appear, will enable serious treatment measures. Subjects and Methods: A total of 105 male hunters without hearing complaints and 45 controls who were not exposed to loud noise were compared and investigated. Extended high-frequency audiograms and conventional audiograms were used to compare the groups. Results: The problem detection rates of conventional high-frequency audiometry, extended high-frequency audiometry, and both tests together were 59.1, 78.1, and 82.9\%, respectively. There was no statistical difference between audiometric values at the extended high-frequency and at the acoustic notch at $4 \mathrm{kHz}$. When the extended high-frequency audiogram was grouped, values at the frequencies of 16,14 , and $12 \mathrm{kHz}$ were affected before that at the acoustic notch at $4 \mathrm{kHz}$. Conclusions: The results of our study indicate that hearing at extended high frequencies was affected before that at conventional high frequencies in individuals exposed to intermittent loud sounds. The first affected extended high frequencies were 16,14 , and $12 \mathrm{kHz}$. Although there was no statistically significant relationship between values at the notch and at extended high frequencies, the presence of a notch at $4 \mathrm{kHz}$, provided that $8 \mathrm{kHz}$ is normal, may indicate a later stage of damage.
\end{abstract}

J Audiol Otol 2022;26(2):83-89

Keywords: Extended high-frequency audiometry; Hearing loss; Noise; Hunters; Firearms.

\section{Introduction}

Firearms are widely used by professionals in the military, private security, and law and enforcement, as well as individuals engaging in hobby sports such as hunting and shooting. Hunting is a very popular hobby in Cyprus, and participants are exposed to intense loud sounds during the hunting season and training. These intermittent loud sounds from firearms can cause irreversible damage to the hunter's auditory system.

Exposure to loud sounds is a major cause of irreversible sensorineural hearing loss. Therefore, hunters should have their hearing checked prior to the appearance of clinical complaints.

This is an Open Access article distributed under the terms of the Creative Commons Attribution Non-Commercial License (https://creativecommons.org/licenses/by-nc/4.0/) which permits unrestricted non-commercial use, distribution, and reproduction in any medium, provided the original work is properly cited.
At this stage, it is extremely important to assess the severity of damage. Once damage has occurred and progressed marginally, the expected findings of standard conventional audiograms for these individuals are normal or an exhibition of mild hearing loss at low frequencies and moderate to severe loss at high frequencies. In addition, an audiometric notch that intensifies at a frequency of $4 \mathrm{kHz}$ is accepted to indicate an early loss of hearing [1].

Recently, some publications have reported that hearing at extended high frequencies (EHFs; $10-20 \mathrm{kHz}$ ) may be affected before any changes are observed in conventional frequencies and audiometric notches in people who have been exposed to intermittent loud sounds [2].

In our study, we studied a group of recreational hunters who used firearms. We found that their speaking frequencies and wideband tympanogram values were normal and that they had 
no complaints of hearing loss or tinnitus. Our research aimed to identify hearing loss at an early stage and assess the damage at this preclinical period by comparing hearing thresholds at conventional high frequencies (CHFs) with EHFs.

\section{Subjects and Methods}

Audiological tests (conventional and extended high-frequency audiograms and broadband tympanograms) of hunters who visited the hospital with complaints other than ear problems were reviewed retrospectively. There were no complaints of tinnitus or hearing loss during anamnesis. The ENT examinations were normal and did not reveal any known systemic diseases such as diabetes mellitus, hypertension, or coronary artery disease. A total of 112 men between the ages of 22 and 45 years, who had been hunting regularly (20 times a year, with an average of 10 shots per day) since the age of 18 , were included in the study. While the study was in progress, 7 patients were excluded because 5 of these patients had previously undetected type 2 diabetes mellitus and 2 had hypertension. In the control group, 45 occupational professionals who satisfied the same criteria but who were not exposed to loud noise were included. The worse ear of each participant was included in the study. All tests were performed in the audiometry laboratory of Near East University using Interacoustics AC 40 (Assens, Denmark) and Interacoustics Titan devices.

We classified the results of conventional high-frequency audiometry (CHFA) and extended high-frequency audiometry (EHFA) in these individuals and investigated the relationships between them. Concurrently, we examined the relationship between audiometric values at the acoustic notch formed at $4 \mathrm{kHz}$ and at EHFs.

In conventional audiometry (CA), frequencies in the range of $0.25-8 \mathrm{kHz}$ from the airway and $0.5-6 \mathrm{kHz}$ from the bone canal were measured. Pulsed tones were delivered on a decibel hearing loss (dB HL) scale, and discrimination scores were determined. The average loss values were calculated by taking the arithmetic average of the threshold values at $0.5,1$, and $2 \mathrm{kHz}$. In EHFA, pulsed tones were measured separately at $10-18-\mathrm{kHz}$ intervals. In the broadband tympanogram, the $\mathrm{V}, \mathrm{P}, \mathrm{C}, \mathrm{G}$, and resonance frequencies were measured. A threshold increase of more than $25 \mathrm{~dB}$ at any $\mathrm{CHF}(4,6$, or 8 $\mathrm{kHz}$ ) was considered a problem-acceptance criterion for CHFA. Likewise, a threshold increase of more than $25 \mathrm{~dB}$ at any $\mathrm{EHF}(10,12,14,16$, or $18 \mathrm{kHz})$ was considered a problem criterion for EHFA.

Demographic characteristics of individuals such as age, gender, occupation, and audiometry results were recorded in an Excel format, and data were analyzed using SPSS V23
(IBM Corp., Armonk, NY, USA). Conformity to a normal distribution was evaluated using the Kolmogorov-Smirnov and Shapiro-Wilk tests. The chi-square test was used to compare categorical variables across groups. Independent two-sample t-tests were used to compare normally distributed data according to paired groups, and the Mann-Whitney U test was used to compare non-normally distributed data. One-way analysis of variance was used to compare normally distributed quantitative data according to groups of three or more, and the Kruskal-Wallis test was used to compare non-normally distributed data. Spearman's rho correlation coefficient was used to examine the relationship between the non-normally distributed data. Results of the analyses are presented as mean \pm standard deviation and median (minimum-maximum) for quantitative data, and as frequency (percentage) for categorical data. The significance level was set at $p<0.050$.

\section{Ethics statement}

This study was approved by the Scientific Research Ethics Committee of Near East University (Research Project Evaluation Report No: 2020/85-1188). Written informed consent was obtained from the participants.

\section{Results}

There was no difference between the hunter and control groups in terms of age or broadband tympanogram results. The mean ages were 32.66 years and 32.59 years, respectively, and the respective average $\mathrm{CA}$ values were $11.21 \mathrm{~dB}$ and $7.69 \mathrm{~dB}$. The tympanometric results were normal in all individuals.

In 62 of 105 hunters $(59.1 \%)$, an increase of hearing threshold was detected in the CHFs $(4,6$, and $8 \mathrm{kHz})$, while the number of hunters with an increase of threshold in any of the EHFs $(10,12,14,16$, and $18 \mathrm{kHz})$ was $82(78.1 \%)$. The number of hunters with an increase in either test was 87 (82.9\%). Only 4 of the 42 patients $(9.5 \%)$ in the control group with a similar mean age showed an increase in CHF threshold values. The number of patients with an increase in any of the EHF threshold values was $9(21.4 \%)$ (Table 1$)$.

There was a significant difference between the distribution of patients who had problems in the EHFA and those who had problems in the CHFA $(p<0.001)$. Furthermore, 91.9\% $(n=57)$ of patients $(n=62)$ who had problems with regard to CHFA were also found to have problems with regard to EHFA. Moreover, $58.1 \%(n=25)$ of those who had normal findings based on CHFA ( $n=43)$ were found to have problems with regard to EHFA. Of the 23 patients who had normal findings with regard to EHFA, only five had problems with regard to CHFA. In the control group, three of the four patients with problems 
Table 1. Comparative results of CHFA and EHFA data in the hunter and control groups

\begin{tabular}{|c|c|c|c|c|c|c|c|c|}
\hline & \multicolumn{6}{|c|}{ CHFA and EHFA together } & \multirow{3}{*}{$\begin{array}{c}\text { Test } \\
\text { statistic }\left(\chi^{2}\right)\end{array}$} & \multirow{3}{*}{$p$} \\
\hline & \multicolumn{3}{|c|}{ Control group $(n=42)$} & \multicolumn{3}{|c|}{ Hunter group $(n=105)$} & & \\
\hline & Normal & Problem & Total & Normal & Problem & Total & & \\
\hline Only EHFA & & & & & & & 77.451 & $<0.001$ \\
\hline Normal & $32(100)$ & $1(10)$ & $33(78.6)$ & $18(100)$ & $5(5.7)$ & $23(21.9)$ & & \\
\hline Problem & $0(0)$ & $9(90)$ & $9(21.4)$ & $0(0)$ & $82(94.3)$ & $82(78.1)$ & & \\
\hline Only CHFA & & & & & & & 31.323 & $<0.001$ \\
\hline Normal & $32(100)$ & $6(60)$ & $38(90,5)$ & $18(100)$ & $25(28.7)$ & $43(41)$ & & \\
\hline Problem & $0(0)$ & $4(40)$ & $4(9.5)$ & $0(0)$ & $62(71.3)$ & $62(59.1)$ & & \\
\hline Total & $32(76.2)$ & $10(23.8)$ & $42(100)$ & $18(17.1)$ & 87 (82.9) & 105 (100) & & \\
\hline
\end{tabular}

The results showed the distribution of patients in the control and hunter groups when CHFA and EHFA were performed together, and when only EHFA alone or only CHFA alone was performed. Data are presented as $\mathrm{n}$ (\%). Problem (threshold increase): For EHFA, detecting a threshold increase of more than $25 \mathrm{~dB}$ at any $\operatorname{EHF}(10,12,14,16$, or $18 \mathrm{kHz})$. For CHFA, detecting a threshold increase of more than $25 \mathrm{~dB}$ at any of the CHFs $(4,6$, or $8 \mathrm{kHz})$. Normal: For EHFA; all EHFs $(10,12,14$, 16, and $18 \mathrm{kHz})$ had a threshold of $25 \mathrm{~dB}$ or better. For CHFA, all CHFs $(4,6$, and $8 \mathrm{kHz})$ had a threshold of $25 \mathrm{~dB}$ or better. $\chi^{2}$ : chi-square test statistic. CHFA, conventional high-frequency audiometry; EHFA, extended high-frequency audiometry; CHF, conventional high-frequency; EHF, extended high-frequency

Table 2. Distribution of EHFA according to CHFA in the control and hunter groups

\begin{tabular}{|c|c|c|c|c|c|c|c|c|}
\hline \multirow{3}{*}{ EHFA } & \multicolumn{6}{|c|}{ CHFA } & \multirow{3}{*}{$\begin{array}{c}\text { Test } \\
\text { statistic }\left(\chi^{2}\right)\end{array}$} & \multirow{3}{*}{$p$} \\
\hline & \multicolumn{3}{|c|}{ Control group $(n=42)$} & \multicolumn{3}{|c|}{ Hunter group $(n=105)$} & & \\
\hline & Normal & Problem & Total & Normal & Problem & Total & & \\
\hline Normal & $32(84.2)$ & $1(25.0)$ & $33(78.6)$ & $18(41.9)$ & $5(8.1)$ & $23(21.9)$ & & \\
\hline Problem & $6(15.8)$ & $3(75.0)$ & $9(21.4)$ & $25(58.1)$ & 57 (91.9) & $82(78.1)$ & 16.953 & $<0.001$ \\
\hline Total & $38(90.5)$ & $4(9.5)$ & $42(100)$ & $43(40.9)$ & $62(59.1)$ & $105(100)$ & & \\
\hline
\end{tabular}

Data are presented as $\mathrm{n}$ (\%). Problem (threshold increase): For EHFA, detecting a threshold increase of more than $25 \mathrm{~dB}$ at any $\operatorname{EHF}(10,12,14,16$, or $18 \mathrm{kHz})$; for CHFA, detecting a threshold increase of more than $25 \mathrm{~dB}$ at any of the CHFs $(4,6$, or $8 \mathrm{kHz})$. Normal: For EHFA, all EHFs $(10,12,14,16$, and $18 \mathrm{kHz})$ had a threshold of $25 \mathrm{~dB}$ or better. For CHFA; all CHFs $(4,6$, and $8 \mathrm{kHz})$ had a threshold of $25 \mathrm{~dB}$ or better. $\chi^{2}$ : chi-square test statistic. CHFA, conventional high-frequency audiometry; EHFA, extended high-frequency audiometry; CHF, conventional high-frequency; EHF, extended high-frequency

with regard to the CHFA values also had problems with regard to their EHFA values, while only one out of the 33 patients with normal EHFA values had problems with regard to their CHFA values (Table 2).

\section{Analysis of CHF groups}

A total of 105 patients with normal findings for conventional low frequencies $(125 \mathrm{~Hz}$ and $250 \mathrm{~Hz})$ and normal speech frequencies $(0.5,1$, and $2 \mathrm{kHz})$ were divided into five groups, taking into account the changes in hearing thresholds at CHFs (4, 6, and $8 \mathrm{kHz}$ ): 1) Group 1, the mean threshold was normal; 2) Group 2, there was an increase at $4 \mathrm{kHz}$, but findings were normal at $8 \mathrm{kHz}$ (a notch was present); 3) Group 3, thresholds at $4 \mathrm{kHz}$ and $8 \mathrm{kHz}$ were increased, but there was an improvement at $8 \mathrm{kHz}$ (a notch was present); 4) Group 4, the threshholds at $4 \mathrm{kHz}$ were normal but increased at the $8-\mathrm{kHz}$ threshold; 5) Group 5, the thresholds at the 4-kHz and 8-kHz were increased, but the increase at $8 \mathrm{kHz}$ was greater (no acoustic notch was observed, and a progressively worsening audiogram was observed). The statistical analysis determined that the median thresholds of all EHFs $(\mathrm{kHz})$ differed between the groups $(p<0.001)$ (Table 3).

As shown in Table 3, the thresholds at EHFs were found to be similar in CHF Groups 1 and 2. A slight threshold increase was detected at $16 \mathrm{kHz}(31.9-44.1 \mathrm{~dB}), 14 \mathrm{kHz}(27.9-36.9$ $\mathrm{dB})$, and $12 \mathrm{kHz}(27.9-32.2 \mathrm{~dB})$ in the groups, although it was worse in Group 2 with notches. In Groups 3 and 4, the detected values at $10,12,14$, and $16 \mathrm{kHz}$ were $53,55,53$, and $52 \mathrm{~dB}$ and $60,64,60$, and $62 \mathrm{~dB}$, respectively. In Group 5, the respective values were 77, 76, 69, and $62 \mathrm{~dB}$ (Table 3).

In the study group, 47 patients were recorded to have a notch (increased at the $4-\mathrm{kHz}$ threshold but better at the $8-\mathrm{kHz}$ threshold). In 34 of 47 (72.3\%) patients with a notch, one or more EHF values were increased, while normal EHF values were recorded in $13(27.7 \%)$ patients. However, there was no significant difference between values at the acoustic notch at $4 \mathrm{kHz}$ and the threshold increase at EHFs $(10-18 \mathrm{kHz})(p=$ 0.199) (Table 4).

\section{Analysis of threshold increases at EHFs}

A total of 105 patients were divided into six groups based on the mean values of the EHF hearing thresholds, and these 


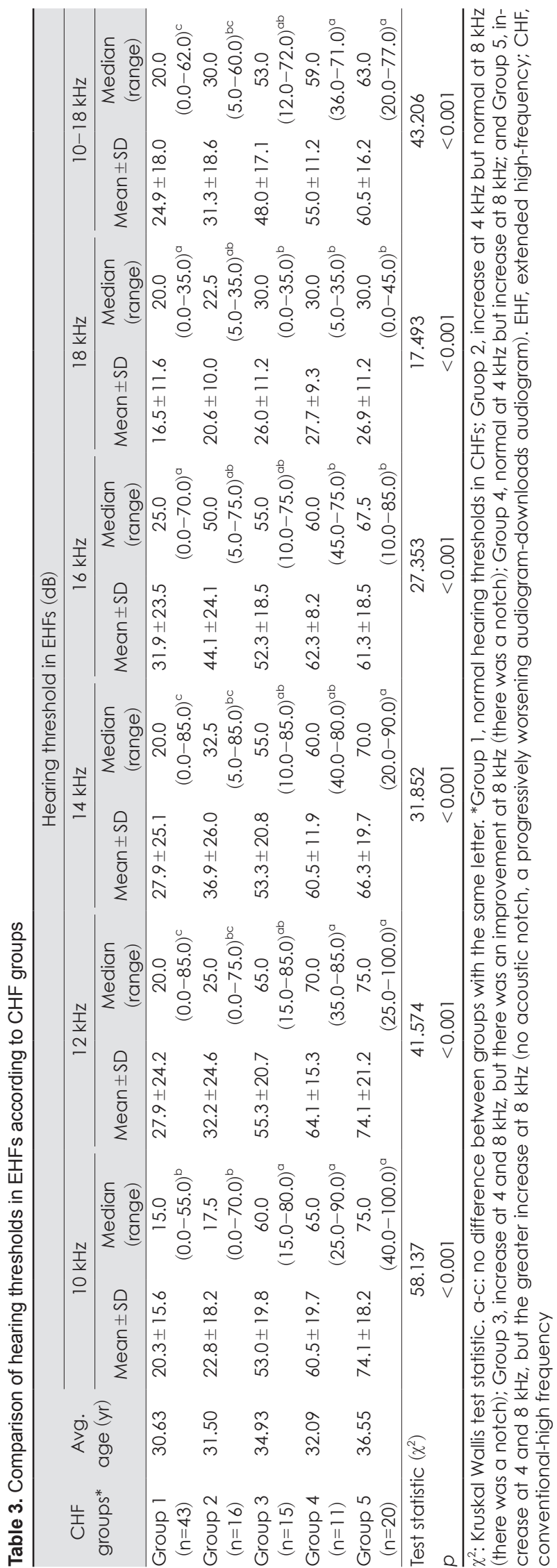

Table 4. Affected status of EHFs according to the presence of a notch

\begin{tabular}{|c|c|c|c|c|c|}
\hline \multirow{2}{*}{ EHF } & \multicolumn{2}{|c|}{ Notch } & \multirow{2}{*}{ Total } & \multirow{2}{*}{$\begin{array}{c}\text { Test } \\
\text { statistic }\left(\chi^{2}\right)\end{array}$} & \multirow{2}{*}{$p$} \\
\hline & No & Yes & & & \\
\hline Normal & $10(17.2)$ & $13(27.7)$ & $23(21.9)$ & & \\
\hline Problem & $48(82.8)$ & $34(72.3)$ & $82(78.1)$ & 1.647 & 0.199 \\
\hline Total & 58 & 47 & 105 & & \\
\hline
\end{tabular}

Data are presented as $\mathrm{n}$ (\%). Problem (threshold increase): For EHFA, detecting a threshold increase of more than $25 \mathrm{~dB}$ at any $\operatorname{EHF}(10,12,14,16$, or $18 \mathrm{kHz})$. Normal: For EHFA, all EHFs $(10,12$, 14,16 , and $18 \mathrm{kHz}$ ) had a threshold of $25 \mathrm{~dB}$ or better. EHF, extended high-frequency; EHFA, extended high frequency audiometry

groups were compared with their mean thresholds at CHFs: 1) Group 1, the average threshold $<25 \mathrm{~dB}$; 2) Group 2, 25-34 dB; 3) Group 3, 35-44 dB; 4) Group 4, 45-54 dB, 5) Group $5,55-64 \mathrm{~dB}$, and 6) Group $6 \geq 65 \mathrm{~dB}$.

The average thresholds of the graded and grouped EHF are compared with the average CHF values in Table 5. A significant difference was found between the median values at $4 \mathrm{kHz}$ and $8 \mathrm{kHz}$ between the groups $(p<0.001)$. The median thresholds of Groups 1 to 6 at $4 \mathrm{kHz}$ were 15, 20,25, 30,35, and 70 $\mathrm{dB}$, respectively, and were $10,15,27.5,25,60$, and $80 \mathrm{~dB}$ for $8 \mathrm{kHz}$. The highest median thresholds were obtained from Group 6, while the lowest median thresholds were obtained from Group 1. The mean ages of the groups were 28.11, 30.78, $33.42,36.71,33.83$, and 37.87 years, respectively (Table 5).

The analysis showed that although the mean CHF thresholds were normal in the Groups 1 and 2, the values at $8 \mathrm{kHz}$ were better than those at $4 \mathrm{kHz}$ (notches were present). In Groups 3 and 4, the thresholds at 4,6 , and $8 \mathrm{kHz}$ were slightly increased at the same level. The threshold values at 4, 6, and $8 \mathrm{kHz}$ increased gradually in Groups 5 and 6 , respectively. In Groups 1, 2 and 3, the most affected frequencies among the EHFs were 16, 14, and $12 \mathrm{kHz}$. In Group 6, which exhibited the worst findings, thresholds at $8 \mathrm{kHz}$ in the $\mathrm{CHF}$ were affected as much as the EHF values (Fig. 1).

\section{DISCUSSION}

Hunting with firearms is a popular recreational sport in northern Cyprus. Hunters in Cyprus use 12 caliber rifles with 70-mm cartridges with a recorded loudness of $140 \mathrm{~dB}$ peSPL [2]. The World Health Organization has determined $120 \mathrm{~dB}$ peSPL for short, sudden, and high sounds to be safe. Without ear protection, sounds higher than $120 \mathrm{~dB}$ peSPL can potentially damage the hearing system.

However, despite this harmful effect, hunters in northern Cyprus do not use ear protectors on the pretext that it limits their hunting ability. Avoiding ear protectors is also common 
Table 5. Comparison of hearing thresholds in CHFs (4 kHz and $8 \mathrm{kHz}$ ) according to the EHF group

\begin{tabular}{|c|c|c|c|c|c|}
\hline \multirow{3}{*}{ EHF groups* } & \multirow{3}{*}{ Avg. age (yr) } & \multicolumn{4}{|c|}{ Hearing threshold in CHFs (dB) } \\
\hline & & \multicolumn{2}{|c|}{$4 \mathrm{kHz}$} & \multicolumn{2}{|c|}{$8 \mathrm{kHz}$} \\
\hline & & Mean \pm SD & Median (range) & Mean \pm SD & Median (range) \\
\hline Group $1(n=35)$ & 28.11 & $19.5 \pm 16.9$ & $15.0(0.0-65.0)^{c}$ & $14.4 \pm 15.2$ & $10.0(0.0-80.0)^{d}$ \\
\hline Group $2(n=9)$ & 30.78 & $24.6 \pm 17.2$ & $20.0(5.0-65.0)^{\mathrm{bc}}$ & $15.8 \pm 8.2$ & $15.0(5.0-30.0)^{\mathrm{cd}}$ \\
\hline Group $3(n=12)$ & 33.42 & $28.8 \pm 17.9$ & $25.0(5.0-65.0)^{\mathrm{abc}}$ & $27.9 \pm 17.8$ & $27.5(5.0-60.0)^{\mathrm{bcd}}$ \\
\hline Group $4(n=17)$ & 36.71 & $33.8 \pm 22.9$ & $30.0(10.0-85.0)^{a b c}$ & $35.6 \pm 22.0$ & $25.0(15.0-75.0)^{\mathrm{bc}}$ \\
\hline Group $5(n=17)$ & 33.83 & $43.8 \pm 25.1$ & $35.0(15.0-85.0)^{a b}$ & $53.8 \pm 23.4$ & $60.0(20.0-85.0)^{\mathrm{ab}}$ \\
\hline Group $6(n=15)$ & 37.87 & $62.0 \pm 25.6$ & $70.0(20.0-95.0)^{a}$ & $75.7 \pm 20.3$ & $80.0(30.0-110.0)^{a}$ \\
\hline Test statistics $\left(\chi^{2}\right)$ & & \multicolumn{2}{|c|}{32.56} & \multicolumn{2}{|c|}{61.305} \\
\hline$p$ & & \multicolumn{2}{|c|}{$<0.001$} & \multicolumn{2}{|c|}{$<0.001$} \\
\hline
\end{tabular}

$\chi^{2}$ : Kruskal-Wallis test statistic, a-d: No difference between groups with the same letter. *EHFs grouped based on the mean hearing thresholds in EHFs (at 12, 14, 16, and $18 \mathrm{kHz}$ ). Group 1, average thresholds <25 dB; Group 2, 25-34 dB; Group 3, 35-44 dB; Group 4, 45-54 dB; Group 5, 55-64 dB; and Group 6, $\geq 65 \mathrm{~dB}$. CHF, conventional high-frequency; EHF, extended high-frequency; CHF, conventional high-frequency; EHF, extended high-frequency

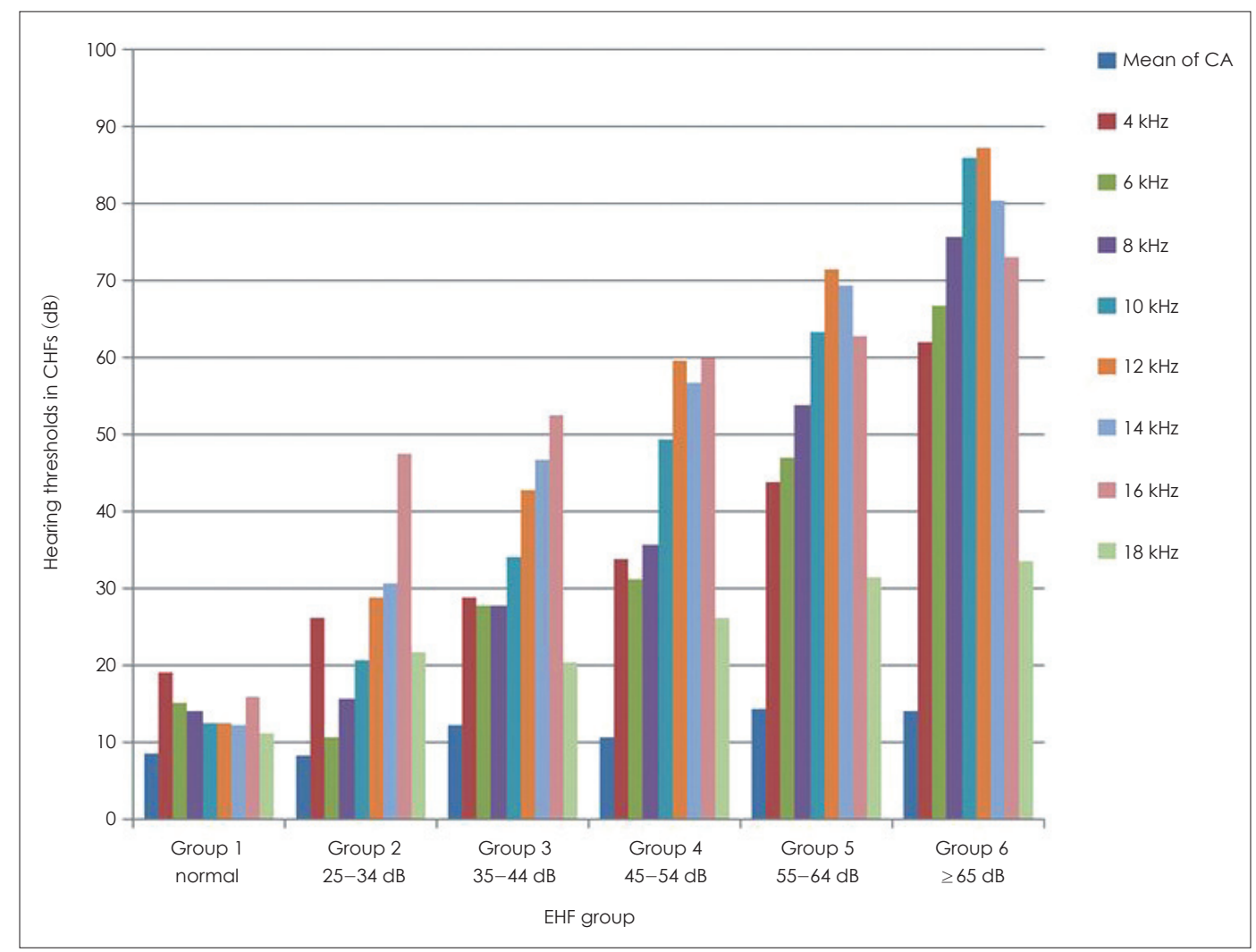

Fig. 1. Analysis of EHF groups. CA, conventional audiogram; EHF, extended high-frequency.

in other parts of the world [3].

It is crucial to detect and grade the damage that occurs before hearing problems manifest, because it may lead to a more rigorous implementation of necessary protective measures. Conventional audiograms used in standard diagnosis are insufficient to show damage during this preclinical period. Although some publications have reported the contrary [4,5], many studies have shown that the most sensitive method for detecting damage to the hearing system in people exposed to loud noise is EHFA [6-10]. However, very few studies have investigated the relationship between acoustic notches and EHFA, and our literature search did not find any studies regarding the classification of audiological findings in the pre-clinical period.

Previous studies $[2,9,10,11]$ found that EHFA $(10-16 \mathrm{kHz})$ is more sensitive than $\mathrm{CA}(0.5-8 \mathrm{kHz})$ in detecting the early effects of damage due to exposure to dangerously loud noises. Mehrparvar compared EHFA with CA and DPOAEs (0.5-6 $\mathrm{kHz}$ ) and found that EHFA was more sensitive. In addition, 
Türkkahraman et al. [12] and Mehrparvar et al. [2] found in their studies that audiometric values at $14 \mathrm{kHz}$ and $16 \mathrm{kHz}$ were more sensitive to hazardous noise than those at other frequencies. In a study conducted on civilian pilots, significant elevations were found in the hearing threshold in both CA and EHFA; however, these threshold increases were more pronounced in EHFA. In the same study, significant differences were observed in EHFA in pilots with normal hearing thresholds in CA [13]. In Gordon et al.'s study [14] of people who had just left the army, 29\% exhibited a threshold above $20 \mathrm{dBL}$ in CA, whereas this rate was $42 \%$ in EHFA. Rodríguez Valiente et al. [15] showed that one of the 11 examples in which EHFA is useful for the early detection of hearing loss in people with normal CA is hearing loss due to loud sounds (in musicians).

However, some studies have found conflicting results regarding the relationship between noise exposure and EHF hearing threshold shifts. Silvestre et al. [16] reported no correlation between hearing threshold shifts at all high frequencies in individuals exposed to personal stereo devices. The fact that these studies considered only one leisure time activity without considering many other activities may explain these inconsistent results [16]. In the study by Balatsouras et al. [5], individuals exposed to impulse noises were evaluated using EHFA, and no statistically significant threshold difference was found between CA and EHFA in these studies.

In our study, the detection rate of EHF threshold increase was $78.1 \%$ and the rate of CHF threshold increase was only $59.1 \%$. The rate increased to $82.9 \%$ when the two tests were performed together (Table 1). In addition, 25 (58.1\%) patients $(n=43)$ with normal CHF thresholds showed an increase in EHF thresholds, whereas an increase in CHF thresholds was observed in only $5(8.1 \%)$ of 23 patients with normal EHF values. CHF findings were found to be normal in 25 of 82 patients with an increased EHF threshold, while EHF findings were found to be normal in only 5 of 62 patients with an increased CHF threshold (Table 2). These results show that EHFA is more sensitive than CA in detecting damage to the auditory system in people exposed to intermittent loud sounds.

Wei et al. [17], who performed one of the first few studies on the acoustic notch and EHFA, found a strong and stable relationship between the hearing threshold shift at 10, 11.2, 12.5 , and $14 \mathrm{kHz}$ and the audiometric notch. Based on this study, they hypothesized that the threshold shift at EHFs might be indicative of an audiometric notch appearance at a later time point.

In our study, there was no statistically significant difference in the distribution of patients with EHF values according to notch status ( $p=0.199)$. We found that 47 of the patients had a notch, and while $72.3 \%$ (34 patients) of this group showed an increase in the EHF values, only $27.7 \%$ had normal EHF findings. At the same time, $48(82.8 \%)$ of the 58 patients who did not exhibit a notch had problems according to EHF values (Table 4). These findings demonstrate the importance of EHFA in detecting cochlear damage with or without a notch.

In the groups based on changes in CHF values, we detected an average threshold increase in intensities at the EHFs in parallel with the threshold increase intensities recorded at CHFs. Although hearing at $4 \mathrm{kHz}$ and $8 \mathrm{kHz}$ was normal in Group 1, significant increases in threshold values were observed in the 16, 14, and $12 \mathrm{kHz}$. However, although the EHF values in Group 2 were similar to those in Group 1, an increase was recorded in the $4 \mathrm{kHz}$. These findings suggest that once cochlear damage begins to occur, it first affects the EHFs and then affects both EHFs and CHFs. The most sensitive EHFs at this initial stage were 16,14 , and $12 \mathrm{kHz}$. In the next stage, it seems that $4 \mathrm{kHz}$ is affected. In later stages, as more serious hearing losses begin to occur in the EHFs, the $8 \mathrm{kHz}$ and $4 \mathrm{kHz}$ are affected (Table 3).

In the analysis of threshold increases with regard to EHFs, in Group 1, whose mean threshold values for EHF and CHF were within normal limits, there was a slight increase in thresholds at $16 \mathrm{kHz}$ and $4 \mathrm{kHz}$ (Fig. 1), which did not exceed the normal limits detected. In Group 2, which showed a slight increase in the mean EHF threshold values, a very slight increase at $4 \mathrm{kHz}$ (mean $26.26 \mathrm{~dB}$ ) and a mild increase at $16 \mathrm{kHz}$ (mean $47.08 \mathrm{~dB}$ ) were observed. This suggests that $16 \mathrm{kHz}$ plays an important role in detecting damage during the early period. At $4 \mathrm{kHz}$, it is notable that it increased within normal limits in Group 1 and showed a slight increase, such as at $12 \mathrm{kHz}$ and $14 \mathrm{kHz}$, in Group 2. Although we could not find a significant relationship between the acoustic notch and extended high frequencies, it should be kept in mind that these findings may indicate the next stage of damage, and further research should be conducted.

In Groups 3 and 4 with mean EHF threshold values in the $35-54 \mathrm{~dB}$ range, the notch at $4 \mathrm{kHz}$ disappeared. In Groups 5 and 6 , whose average threshold value was above $55 \mathrm{~dB}$, average values at $8 \mathrm{kHz}$ were seen to increase more than the average threshold values at $4 \mathrm{kHz}$; that is, they gained a download feature. In other words, as the average threshold values of the EHFs increased, the threshold values increased at $4 \mathrm{kHz}$ and were equalized at $4-8 \mathrm{kHz}$. Finally, in advanced cases, the CHF audiogram gained a download feature (Table 5, Fig. 1).

In addition, the threshold increased at $8 \mathrm{kHz}$, and the EHFs showed parallelism. This indicates that the threshold increase in the 8-kHz range may be an indicator of a poor prognosis for individuals exposed to intermittent loud sounds. 
As can be seen in Table 5, there is a parallelism between increases in mean EHF thresholds and age (time to noise exposure). Although the study group was similar in age to the control group, differences in the duration of exposure to noise between subjects is a limitation of the study.

By considering the total number of patients, the detection rates of increase in hearing threshold values for CA, EHFA, and for both tests performed together were $59.1 \%, 78.1 \%$, and $82.9 \%$, respectively. This shows that we can detect a much higher rate of early-stage hearing problems in hunters who do not have clinical hearing problems by performing EHFA and CA together, instead of CA alone.

In our study, an increase of threshold in EHFs was first detected in those exposed to intermittent loud sounds, even if CHFs were not affected. The first affected EHFs were $16 \mathrm{kHz}$, $14 \mathrm{kHz}$, and $12 \mathrm{kHz}$. Although there was no statistically significant relationship between values at the notch and at the EHFs, the presence of a notch at $4 \mathrm{kHz}$, provided that $8 \mathrm{kHz}$ is normal, may indicate a later stage of damage. However, this hypothesis must be supported by further studies. In a later stage of the damage, it was observed that the threshold at 8 $\mathrm{kHz}$ was first equalized to that at $4 \mathrm{kHz}$, and that the EHF thresholds increased even further. In the final stage, the threshold at $8 \mathrm{kHz}$ was more affected than that at $4 \mathrm{kHz}$, and the increase in the EHFs progressed further.

By using EHFA, damage to the hearing system can be detected early, and preventive measures can be taken more carefully, leading to better quality of life and hearing health.

\section{Acknowledgments}

We would like to thank the hunters who participated in this study and our colleagues in the audiology department of Near East University for performing auditory tests.

\section{Conflicts of interest}

The authors have no financial conflicts of interest.

\section{Author Contributions}

Conceptualization: Remzi Tinazli. Data curation: Remzi Tinazli, Mehtap Tinazli. Formal analysis: Remzi Tinazli. Investigation: Remzi Tinazli, Mehtap Tinazli. Methodology: Remzi Tinazli. Project administration: Remzi Tinazli, Mehtap Tinazli. Resources: Remzi Tinazli. Software: Remzi Tinazli, Mehtap Tinazli. Supervision: Remzi Tinazli. Validation: Remzi Tinazli, Mehtap Tinazli. Visualization: Remzi Tinazli. Writing — original draft: Remzi Tinazli, Mehtap Tinazli. Writing - review \& editing: Remzi Tinazli, Mehtap Tinazli. Approval of final manuscript: Remzi Tinazli, Mehtap Tinazli.

\section{ORCID iDs}

Remzi Tinazli

Mehtap Tinazli

https://orcid.org/0000-0003-3066-4804

https://orcid.org/0000-0002-7858-0696

\section{REFERENCES}

1) ACOEM Noise and Hearing Conservation Committee. ACOEM evidence-based statement. Noise-induced hearing loss. J Occup Environ Med 2003;45:579-81.

2) Mehrparvar AH, Mirmohammadi SJ, Davari MH, Mostaghaci M, Mollasadeghi A, Bahaloo M, et al. Conventional audiometry, extended high-frequency audiometry, and DPOAE for early diagnosis of NIHL. Iran Red Crescent Med J 2014;16:e9628.

3) ideal AV. Jet sound shotshell 12 gauge $140 \mathrm{Db}$ [Internet]. Seyhan: ideal AV; [cited 2021 October 1]. Available from: URL: https:// www.idealav.com.tr/jet-sound-shotshell-12-cal-140-db.

4) Laffoon SM, Stewart M, Zheng Y, Meinke DK. Conventional audiometry, extended high-frequency audiometry, and DPOAEs in youth recreational firearm users. Int J Audiol 2019;58(sup1):S40-8.

5) Balatsouras DG, Homsioglou E, Danielidis V. Extended high-frequency audiometry in patients with acoustic trauma. Clin Otolaryngol 2005;30:249-54.

6) Kuronen P, Sorri MJ, Pääkkönen R, Muhli A. Temporary threshold shift in military pilots measured using conventional and extended high-frequency audiometry after one flight. Int J Audiol 2003;42:2933.

7) Beahan N, Kei J, Driscoll C, Charles B, Khan A. High-frequency pure-tone audiometry in children: a test-retest reliability study relative to ototoxic criteria. Ear Hear 2012;33:104-11.

8) Mehrparvar AH, Mirmohammadi SJ, Ghoreyshi A, Mollasadeghi A, Loukzadeh Z. High-frequency audiometry: a means for early diagnosis of noise-induced hearing loss. Noise Health 2011;13:402-6.

9) Porto MA, Gahyva DL, Lauris JR, Lopes AC. [Audiometric evaluation in extended high frequencies of individuals exposed to occupational noise]. Pro Fono 2004;16:237-50.

10) Somma G, Pietroiusti A, Magrini A, Coppeta L, Ancona C, Gardi S, et al. Extended high-frequency audiometry and noise induced hearing loss in cement workers. Am J Ind Med 2008;51:452-62.

11) Wang Y, Yang B, Li Y, Hou L, Hu Y, Han Y. [Application of extended high frequency audiometry in the early diagnosis of noise--induced hearing loss]. Zhonghua Er Bi Yan Hou Ke Za Zhi 2000;35: 26-8.

12) Türkkahraman S, Gök U, Karlidağ T, Keleş E, Oztürk A. [Findings of standard and high-frequency audiometry in workers exposed to occupational noise for long durations]. Kulak Burun Bogaz Ihtis Derg 2003;10:137-42.

13) Ma F, Gong S, Liu S, Hu M, Qin C, Bai Y. Extended high-frequency audiometry $(9-20 \mathrm{kHz})$ in civilian pilots. Aerosp Med Hum Perform 2018;89:593-600.

14) Gordon JS, Griest SE, Thielman EJ, Carlson KF, Helt WJ, Lewis MS, et al. Audiologic characteristics in a sample of recently-separated military Veterans: the noise outcomes in servicemembers epidemiology study (NOISE Study). Hear Res 2017;349:21-30.

15) Rodríguez Valiente A, Roldán Fidalgo A, Villarreal IM, García Berrocal JR. Extended high-frequency audiometry (9,000-20,000 $\mathrm{Hz}$ ). Usefulness in audiological diagnosis. Acta Otorrinolaringol Esp 2016;67:40-4

16) Silvestre RA, Ribas Â, Hammerschmidt R, de Lacerda AB. Highfrequency profile in adolescents and its relationship with the use of personal stereo devices. J Pediatr (Rio J) 2016;92:206-11.

17) Wei W, Heinze S, Gerstner DG, Walser SM, Twardella D, Reiter C, et al. Audiometric notch and extended high-frequency hearing threshold shift in relation to total leisure noise exposure: an exploratory analysis. Noise Health 2017;19:263-9. 